\title{
CRITICAL STUDY OF METHODS OF MEASURING THE BULK OF PAPER
}

\author{
By F. T. Carson
}

\section{ABSTRACT}

Because of the prevalence in the paper industry of diverse methods of measuring the property of bulk or voluminousness of paper, a study has been made of methods commonly used, and as a result of this investigation a standard method is proposed for measuring bulk. It was found that the different pressures used in the variable-pressure type of apparatus, and the use of an insufficient number of sheets in the case of measurements with thickness gages, are chiefly responsible for the diversity of results ordinarily obtained. As a result of comparative tests made on different types of apparatus and at various pressures, it was found possible to select procedures for the two most commonly used measuring devices so as to bring them into substantial agreement with each other and with the bulk actually obtaining in bound volumes.

A standard procedure is recommended which permits either the measurement of a pack of paper 0.1 inch or more in thickness with a thickness gage of standard type, or the measurement of a 1 -inch pack under a pressure of $5 \mathrm{lbs}$./in. ${ }^{2}$ by means of a pressure bulker. It is recommended that the results be expressed as $(a)$ bulking thickness, or the thickness in hundredths of an inch of a 100-sheet pack; and $(b)$ specific bulk, or the ratio of bulking thickness to the standard ream weight of the paper measured.

\section{CONTENTS}

I. Introduction

III. Study of methods of measuring bulk _

作 1041

(a) Effect of size of sheets...... 1042

(b) Effect of size of pressure surfaces . .

(c) Effect of thickness of pack

(d) Effect of pressure

2. Thickness gages...... 1045

(a) Pressure of thickness gages....... 1046

(b) Measurement on single sheets and on a pack of paper - 1047

(c) Effect of humidity in bulk measurement._...... 1048

3. Bulking press to apply uniformly distributed pressure......- 1048

IV. Comparative tests by three methods.

V. Conclusions and recommendations

1. Negligible effect of preliminary heavy pressure

2. Choice of method

3. Expression of results_._._._. 1055

4 Recommended standard procedure 


\section{INTRODUCTION}

The property of paper known as bulk is one of those vaguely defined characteristics frequently encountered in the older, empiric industries which may have varied interpretations and means of measurement. Because of the lack of any recognized standard procedure for the evaluation of this property, the Bureau of Standards, in cooperation with the Technical Association of the Pulp and Paper Industry in their program of standardizing paper-testing methods, has recently made a study of the measurement of the bulk of paper.

According to the varied usage of the term in the paper industry, bulk may mean (a) the thickness of a certain number of sheets, (b) the number of sheets in a 1-inch pack, $(c)$ the thickness of a single sheet, $(d)$ the ratio of thickness to ream weight, $(e)$ specific volume, $(f)$ the ratio of apparent volume to fiber volume. But in any discussion of bulk there is usually the idea, expressed or implied, of something equivalent to or proportional to specific volume. Bulkiness is thought of in terms of the thickness which a sheet of a given area can be made to have with a given amount of paper-making material. It is the antithesis of denseness or compactness.

The measurement of bulk is of importance chiefly to publishers and bookbinders and to the manufacturers who contract to supply paper to these converters. Because it is customary to prepare the bindings for books while the pages are being printed, it is necessary to know beforehand how thick a book is going to be. At one extreme, a premium is placed upon bulky paper, as, for example, in popular novels which are usually desired to be as thick as possible for a given weight of material. At the opposite extreme, paper having a low bulk is a desideratum, as, for example, in dictionaries and encyclopedias.

\section{METHODS OF MEASUREMENT}

According to the methods in common use for determining bulk the principal measurement is that of thickness made on one or more sheets. In practice this measurement may be made on any amount of paper, varying from a single sheet to a pack several inches thick. The paper is compressed more or less during the measurement, but there is little uniformity with respect to the pressures customarily used. The weight of the paper may or may not be taken into consideration, depending upon requirements and upon individual practice

The thickness measurement is often made with an ordinary rule held against the edge of a pack of paper which is pressed down with the hand. A sliding caliper or combination square is often used. Sometimes the measurement is merely the thickness of a single sheet determined by means of a micrometer caliper or other type 
of thickness gage, or it may be the thickness of several sheets taken together. Sometimes the measurement is made after compressing the paper in a definite manner, such as by subjecting it to the pressure of a metallic disk of definite weight and cross-sectional area. But apparently only one instrument has been made specifically for the purpose of measuring bulk, the so-called pressure bulker.

\section{STUDY OF METHODS OF MEASURIIYG BULK}

In an investigation with the object of selecting and recommending a standardized procedure it did not seem worth while to consider the procedures involving hand-rule measurements under indefinite hand pressures, since these pressures are not reproducible. After some preliminary study of different procedures three were selected for study and comparison. These are (a) measurement with the pressure bulker, (b) measurement by means of thickness gages, (c) measurement of the thickness of a pack of paper under pressure uniformly distributed over the entire pack.

\section{PRESSURE BULKER}

In this apparatus, which is illustrated in Figure 1, a pack of paper is clamped between two horizontal surfaces, the movable one of which communicates with a spring pressure gauge which indicates, in pounds per square inch, the pressure which is applied to the pack of paper. The surfaces are circular in form and have an area of 3 square inches each. A pointer attached to the movable pressure foot indicates on a vertical scale the distance between the two horizontal surfaces, which distance is the thickness of the pack. The scale supplied with the instrument is graduated in inches, and the smallest subdivisions are thirty-seconds of an inch. Pressure is applied by means of a screw jack turned with a hand wheel. The bulker is capable of exerting an indicated pressure of 50 lbs./in. ${ }^{2}$, and can accommodate a pack of paper of any thickness up to 4 inches.

It was found in the instrument under examination that the guide stem of the pressure foot did not work freely. Its movement was very sluggish, and the pressure gauge did not respond readily to the pressures applied. The interior of the casting was found to be covered with molder's sand, some of which had become mixed with the lubricant and had given rise to considerable friction. After the interior and the moving parts had been thoroughly cleaned and the mechanism had been oiled the friction was greatly reduced, although an appreciable amount was still in evidence.

The pressure gauge was calibrated in an Amsler machine of 600 pounds capacity, a compression tester of the inclined balance type. The gauge was removed from the bulk tester and calibrated in its 
normal upright position. It was necessary, therefore, to add the weight of the gauge to the applied pressure in each case in order to get the total pressure exerted by the pressure foot on the surface underneath it. The actual pressure, in pounds per square inch, exerted by the pressure foot for each calibrated-scale division was found by dividing this total pressure by three, the area in square inches of the pressure foot. It was found that with increasing load the actual pressure differed from the nominal pressure by amounts ranging from 1 to 5 per cent. The differences were not consistently positive or negative throughout, although for the higher pressures the actual pressures were greater than the nominal pressures. The differences between actual pressures exerted when using increasing load and when using decreasing load amounted in some cases to as much as 25 per cent for the lower gauge readings, although for the most part these differences, which are indicative of friction in the mechanism, did not exceed 5 per cent.

The bulk tester was fitted with a scale graduated in hundredths of an inch instead of the less-convenient scale supplied with the tester. It was then studied in operation in order to determine the effect upon the bulk test of a number of factors, such as the size of the sheets of paper, the thickness of the pack measured, the amount of pressure applied, the duration of the pressure, and the size of the pressure surfaces.

(a) Effect of Size of Sheets.-When a given pressure is applied to a given area of a pack of paper, the marginal portion of the pack outside of the direct influence of the pressure surface adds a certain resistance to that which the paper directly beneath the pressure surface offers to compression. It seemed that the size of this marginal area might influence the degree of compression of the pack. Since the greatest influence of this nature is to be expected from the most compressible paper, a sample of newsprint, which was the most compressible paper studied, was cut into two packs 4 by 5 inches and 8 by 10 inches, respectively, and tested for thickness under different pressures. The 8 by 10 pack appeared to be slightly thicker at a given pressure. This test, however, did not seem conclusive in view of the fact that the individual sheets of paper differ somewhat in thickness in a given sample. The 8 by 10 pack was, therefore, measured for thickness and was then cut into 4 by 5 packs which were again measured in the same places as before and under the same pressures, ranging from 0.5 to $40 \mathrm{lbs}$./in. ${ }^{2}$. The two sets of readings, recorded to the nearest hundredth of an inch, were identical. Since the readings on the 4 by 5 pack were taken after those on the 8 by 10 pack, any influence which previous pressure might have on the measured thickness of the smaller pack would tend to exaggerate the difference, if any, between the two sets of measurements. But 
as no differences found in the two sets of readings in the latter test, it seemed valid to conclude that sheet size greater than about 4 or 5 inches square has no appreciable effect on bulk measurements as made by the pressure bulker. This conclusion was confirmed by tests in which a dial-thickness gage was attached to the bulker so as to permit of readings to thousandths of an inch. It was found that at a given pressure the thickness of a pack 8 inches square exceeded that of a pack 4 inches square by about 0.1 per cent for pressures ranging from 5 to $50 \mathrm{lbs}$./in. ${ }^{2}$. This difference could not be detected in the ordinary use of the bulk tester.

(b) Effect of Size of Pressure Surfaces.-This effect is not unlike that due to sheet size. By increasing the size of the pressure surface the marginal area for a pack of given area is decreased. Measurements were made on a 4 by 5 inch pack of newsprint with pressure surfaces of 1,3 , and 5 square inches in area and for pressures ranging from 0.5 to $40 \mathrm{lbs}$./jn. ${ }^{2}$. The thickness data, recorded to the nearest hundredth of an inch, showed no appreciable differences for the three surfaces for a given pressure per unit surface. Measurements made to thousandths of an inch by means of the dial gage showed that for a given pressure per unit surface the thickness of a pack of book paper between surfaces 1 square inch in area exceeded that between surfaces 5 square inches in area by less than 0.2 per cent.

(c) EFfect of Thickness of Pack.-It is usually considered that an accuracy of about 10 per cent in bulk standards and specifications is sufficient. Hence, it seems desirable that the measurement be accurate to within at least 1 per cent. For this reason the pack to be measured should be not less than about 1 inch in thickness when the scale graduated in hundredths of an inch is used and should be somewhat thicker for measurement with the scale permitting readings estimated to the nearest sixty-fourth of an inch. The necessary thickness of the pack is largely determined by the degree of refinement in the thickness measurement. When the dial gage was used, permitting readings to thousandths of an inch, readings could be repeated fairly consistently on packs which were thicker than about 0.05 inch, the concordance being better the thicker the packs. The use of a thick pack also affords a better chance of obtaining a fair sample.

(d) Effect of Pressure.-The most important variable in bulk measurements is the pressure applied to the pack while the thickness measurement is being made. The thickness varies considerably according to the pressure applied, and the effect is different for different kinds of paper. The relation between thickness and pressure is not linear. A given pressure change in the lower pressure region has a greater effect on thickness than does an equivalent pressure change 
in the higher pressure region. Some typical dat are presented in Figure 2 to show the effect on bulk measurement of different pressures and different kinds of paper, a pack of 250 sheets being used in each case.

Repeated applications of pressure within the capacity of the bulker did not materially alter the bulk at a given pressure. For example, a pack of the most compressible paper studied was ten

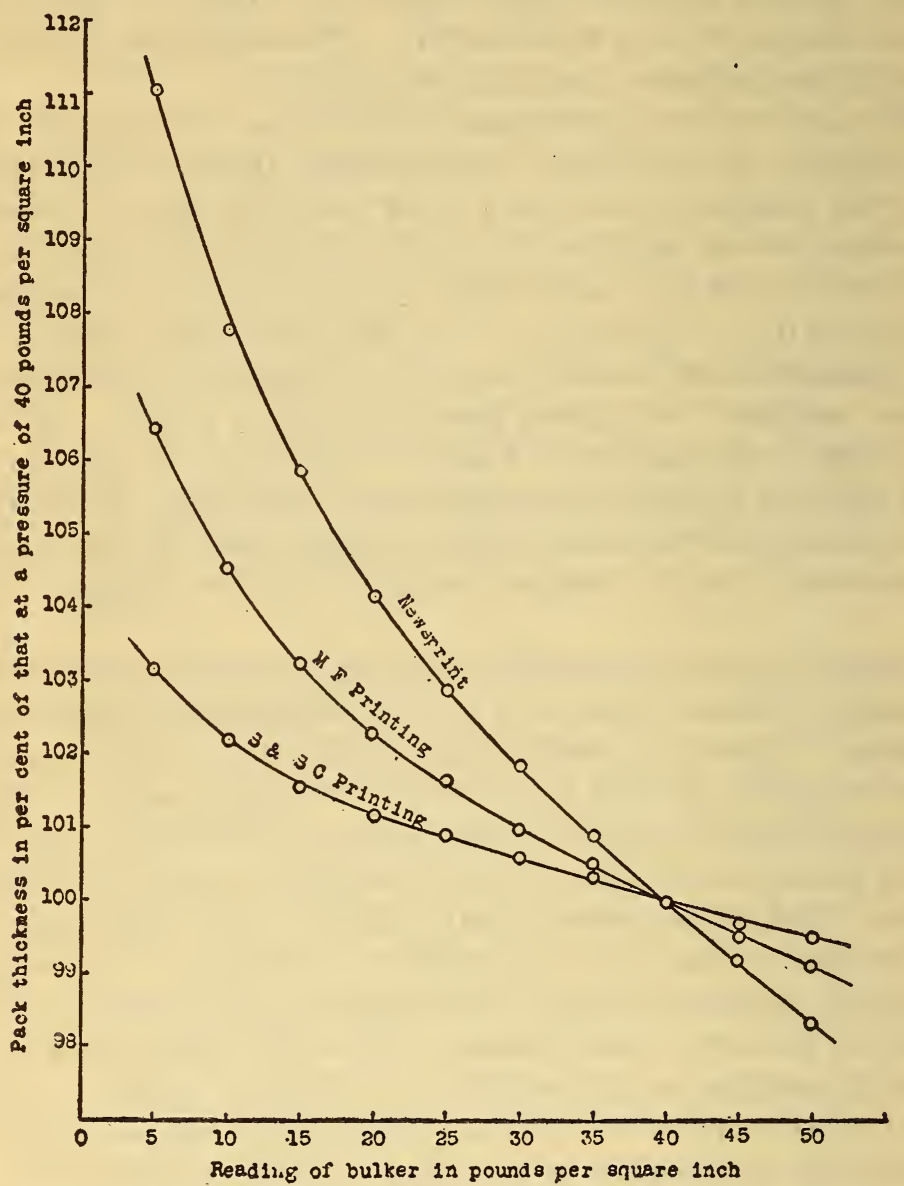

FigdRE 2.-Effect of pressure and type of paper on bulk measurements

times subjected to a pressure of $40 \mathrm{lbs} . / \mathrm{in} .^{2}$ and was found to have lost only 1 per cent of its original thickness at a given pressure. After standing for some time, much of this was recovered. Various tests on different kinds of papers showed that little or none of the thickness is permanently lost by repeated applications of pressures within the capacity of the bulker. It was found that when a small loss appeared to have occurred it could virtually all be restored by 
B. S. Journal of Research, RP69

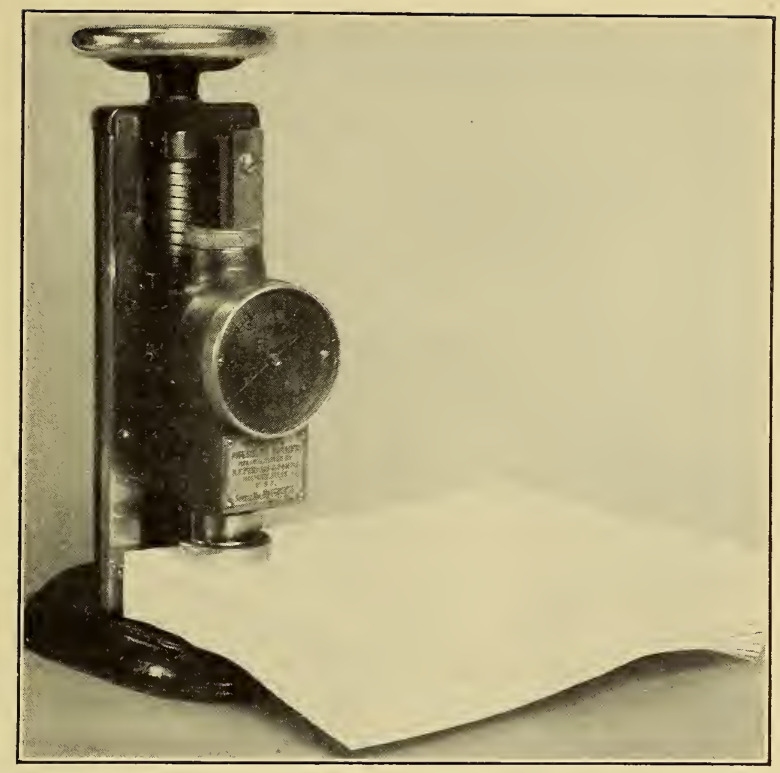

Figure 1.-Pressure bulker

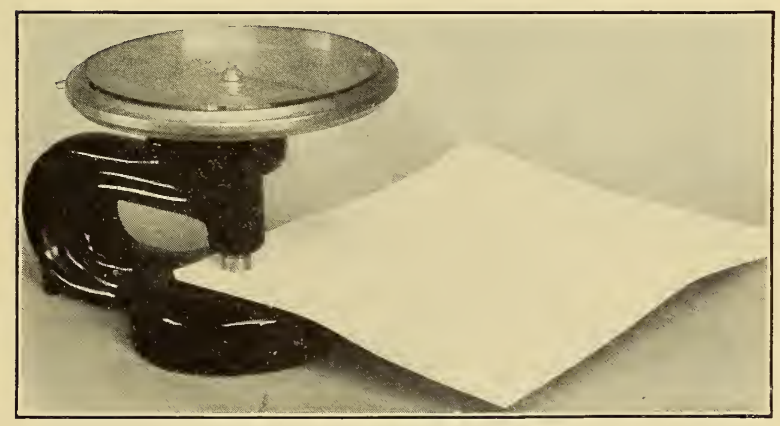

Figure 3.-Thickness gage 
allowing the pack to stand for an hour or so or by flexing and thumbing the pack. Hence, it is evident that the deformation in machinefinished paper resulting from pressures not greater than about 50 lbs./in. ${ }^{2}$ is almost completely elastic. This is not so surprising when it is considered that such papers have previously been subjected to extremely heavy pressure in the calenders during their manufacture, so that the relatively much smaller pressures used in the bulk test have little or no permanent effect upon the papers.

Bulk measurements were made on paper under a pressure of 5 lbs./in. ${ }^{2}$ after having previously subjected the pack to a higher pressure. The test was repeated many times, using various higher pressures to precede the 5-pound pressure. In one series of tests the thickness showed a uniform, slight decrease regardless of the amount of pressure used to precede the 5-pound pressure. The test was repeated, but this time the paper was flexed between each set of measurements so as to enable the pack to recover the temporary decrease in thickness, and pressures from 10 to $50 \mathrm{lbs}$./in. ${ }^{2}$ were used to precede the 5 -pound pressure. The bulk measurements all agreed to within about one-half of 1 per cent.

Tests were made to determine the effect of varying periods of time of application of pressure and of time intervals between operations. Time intervals of 10 to 30 seconds were used, and pressures of 5, 40, 0 , and $5 \mathrm{lbs} . / \mathrm{in} .^{2}$ were applied in sequence. The bulk measurements at a given pressure were in all cases the same. If time intervals of several minutes were allowed, differences might be noted, as is to be surmised from the fact that the small temporary decrease in thickness following the release of pressure is largely recovered within an hour or so. But in the normal, continuous procedure of bulk testing the rate of testing is not a factor in the results.

It appears, therefore, that the important requirements in the use of the pressure bulker are the adoption of a definite pressure at which all bulk measurements are to be made, the calibration of the pressure gauge in this pressure region, and the adoption of a pack thickness sufficient to give the required accuracy in the thickness measurements.

\section{THICKNESS GAGES}

A very common means of estimating the bulk of paper is to measure the thickness of a single sheet or a few sheets with some form of micrometer or thickness gage and then to calculate from this value the number of pages per inch or the thickness of a pack consisting of a large number of sheets. Since the thickness of the usual sheet of paper is of the order of 0.005 inch, it is apparent that measurements made with a micrometer graduated in thousandths of an inch may involve considerable differences when magnified manyfold by such a 
calculation as the above. The percentage error would certainly be greater than the 1 per cent which appears to be the maximum error desirable in bulk measurements. Owing to the probability of a packing effect in an aggregation of sheets, or the fitting of excrescences of one sheet into depressions of another, it seemed doubtful if measurements made on single sheets would total to the same value as a single measurement made on all the sheets at once, even though equal accuracy of measurement were possible in the two cases. This packing effect, if real, would be an important factor in bulk measurement as opposed to thickness measurement on single sheets. Since the pressures exerted by different kinds of thickness gages differ considerably, it seemed possible also that the factor of pressure might influence the results of bulk measurements made by means of thickness gages. In order to determine the rôle of such factors a study was made of this mode of bulk measurement.

(a) Pressure of Thickness Gages.-Two micrometer calipers with ratchet heads, such as are used by machinists, were tested for the pressure exerted by the spindle on the material measured. One end of a lever pivoted at the center was allowed to rest against the end of the spindle and the other end was weighted until the friction on the spindle was sufficient to cause the ratchet to operate. With a smooth brass surface in contact with the spindle one micrometer was found to exert a pressure of about $33 \mathrm{lbs}$./in. ${ }^{2}$ and the other about $27 \mathrm{lbs}$./in. ${ }^{2}$. But with a piece of blotting paper in contact with the spindle the pressure exerted was only about two-thirds as much as for the brass surface. The arresting of the rotation of the spindle depends not only upon the pressure against the spindle, but also on the coefficient of friction between the spindle and the material being measured. Hence, the pressure is different for different kinds of material calipered. For paper the pressure exerted by the spindle of this type of micrometer is in the neighborhood of $20 \mathrm{lbs}$./in. ${ }^{2}$.

A dial micrometer (fig. 3) of a type conforming to the specifications of the Technical Association of the Pulp and Paper Industry was next examined and found to exert a pressure of about $10 \mathrm{lbs}$./in. ${ }^{2}$ on the material being measured.

A pack of newsprint paper about 0.2 inch thick was calipered by means of the dial micrometer and also by means of one of the ratchettype micrometers, the latter exerting about twice the pressure per unit surface as the former. The thickness values obtained with the ratchettype, rotating-spindle micrometer were between 1 and 2 per cent smaller than those obtained with the dial micrometer. This appears to indicate a much smaller influence due to pressure than was found for the bulk tester, a circumstance which is probably to be explained by the much smaller total pressures exerted by the thickness gages and the influence of the marginal area of the pack in leveling out the differences 
which might otherwise exist in making measurements with thickness gages.

(b) Measurement on Single Sheets and on a Pack of Paper.Three sets of measurements were made on 11 different kinds of paper, each consisting of about 20 sheets. The papers were first exposed for at least an hour in the atmosphere where the tests were to be made, after which thickness measurements were made both on the individual sheets and on the entire pack at once. All measurements on each kind of paper were made at the same place on the sheets. One measurement was made on the pack before and another after the individual sheets were calipered, and these two measurements were averaged and compared to the sum of the measurements for the individual sheets. The results were then expressed as the percentage amount by which the sum of the single-sheet measurements differed from the pack thickness. These results are shown in the first three columns of Table 1. The differences range from less than one-half of 1 per cent to more than 7 per cent. Considering the individual measurements made on single sheets, it was found that errors as great as 17 per cent could result in bulk values determined from measurement of a single sheet. Thickness gages available are not sensitive enough for very accurate measurements on single sheets of paper, as a consequence of which errors of measurement on single sheets make it uncertain how significant are the differences noted in the table. But the fact that all these differences are of the same sign is interpreted to mean that the packing effect is real and of some importance in the measurement of bulk.

TABLE 1.-Measurements with thickness gage

\begin{tabular}{|c|c|c|c|c|c|c|c|}
\hline \multirow{2}{*}{ Kind of paper } & \multicolumn{3}{|c|}{$\begin{array}{l}\text { Difference between sum of } \\
\text { single sheets and pack } \\
\text { thickness }\end{array}$} & \multicolumn{2}{|c|}{$\begin{array}{l}\text { Reproducibility } \\
\text { at } 65 \text { R. H.1 }\end{array}$} & \multicolumn{2}{|c|}{$\begin{array}{l}\text { Humidity effect, } \\
65 \text { R. H. to } 30 \text { R. H. }\end{array}$} \\
\hline & 65 R. Н. & 65 R. H. & 30 R. Н. & Pack & $\begin{array}{l}\text { Single } \\
\text { sheets }\end{array}$ & Pack & $\begin{array}{l}\text { Single } \\
\text { sheets }\end{array}$ \\
\hline $\begin{array}{l}\text { Writing } \\
\text { Bond } \\
\text { Ledger } \\
\text { Coated book } \\
\text { S. and S. C. book } \\
\text { Ofiset book. }\end{array}$ & $\begin{array}{r}\text { Per cent } \\
+1.6 \\
+3.0 \\
+1.2 \\
+1.4 \\
+1.2 \\
+3.5\end{array}$ & $\begin{array}{r}\text { Per cent } \\
+1.1 \\
+3.0 \\
+2.5 \\
+1.8 \\
+3.0 \\
+2.8\end{array}$ & $\begin{array}{r}\text { Per cent } \\
+3.9 \\
+2.4 \\
+3.3 \\
+1.9 \\
+3.4 \\
+3.4\end{array}$ & $\begin{array}{r}\text { Per cent } \\
-0.1 \\
-.1 \\
+1.2 \\
+.4 \\
+.4 \\
+.1\end{array}$ & $\begin{array}{r}\text { Per cent } \\
-0.4 \\
-.1 \\
+2.5 \\
+.7 \\
+2.3 \\
-.6\end{array}$ & $\begin{array}{r}\text { Per cent } \\
-1.6 \\
-1.4 \\
-1.3 \\
-1.3 \\
-2.4 \\
-. .8\end{array}$ & $\begin{array}{r}\text { Per cent } \\
+0.7 \\
-1.9 \\
+.8 \\
-.7 \\
-.2 \\
-.8\end{array}$ \\
\hline $\begin{array}{l}\text { Antique book } \\
\text { "Hibulk" book } \\
\text { Mimeograph } \\
\text { Standard newsprint.. } \\
\text { Bulky newsprint }\end{array}$ & $\begin{array}{l}+2.4 \\
+3.3 \\
+4.7 \\
+.4 \\
+6.6\end{array}$ & $\begin{array}{l}+3.7 \\
+4.2 \\
+5.7 \\
+2.0 \\
+7.6\end{array}$ & $\begin{array}{l}+2.9 \\
+3.6 \\
+5.7 \\
+3.2 \\
+7.5\end{array}$ & $\begin{array}{l}+.1 \\
\pm .1 \\
+.1 \\
+.6 \\
+.5\end{array}$ & $\begin{array}{r}+1.5 \\
+.7 \\
+1.0 \\
+2.3 \\
+1.4\end{array}$ & $\begin{array}{l}-1.0 \\
-1.1 \\
-.7 \\
-2.0 \\
-.4\end{array}$ & $\begin{array}{l}-.5 \\
-.9 \\
+.3 \\
+.5 \\
+.4\end{array}$ \\
\hline
\end{tabular}

1 R. H. = per cent relative humidity.

These data are also tabulated in columns 4 and 5 of Table 1 so as to show the precision which may be expected in the case of the two $47559^{\circ}-29-4$ 
procedures. These values represent the percentage differences in duplicate determinations. The agreement of duplicate determinations is much better for measurements on a pack of paper than for measurements on single sheets. Except for the ledger, the agreement is very good for measurements on the pack. The difference in the case of the ledger is probably real, rather than in the nature of an error of measurement, since the time allowed for.conditioning was probably too short for such heavy paper.

The above observations relative to the packing effect and to the precision of measurement show that the current practice of calculating bulk from thickness measurements on a single sheet of paper should be discouraged, and that bulk measurements should always be made on a pack of paper of a thickness commensurate with the sensitivity of the measuring device.

(c) Effect of Humidity in Bulk Measurement.-In the last two columns of Table 1 are presented the percentage differences in the thickness of paper at 65 per cent relative humidity and at 30 per cent relative humidity, as determined both on the packs and on the individual sheets.

The data are expressed as the percentage change in thickness when paper is brought from moisture equilibrium at 65 per cent relative humidity to equilibrium at 30 per cent relative humidity. The results for measurements on single sheets show positive and negative differences about equally divided and confirm previous data to the effect that the influence of humidity changes in this region is of the same order of magnitude as the error of measurement of a single sheet of paper with a micrometer, and that it is, therefore, impossible to determine with certainty by the measurement of a single sheet of paper whether or not its thickness is altered by a change in moisture content. But the data obtained on packs of paper show a consistent decrease in all cases and indicate that the thickness of paper does change according to moisture content. About 2.5 per cent is the greatest difference shown by these data, but additional tests showed that in going from 65 to 15 per cent relative humidity thickness was decreased as much as 8 per cent in the case of one sample of paper.

\section{BULKING PRESS TO APPLY UNIFORMLY DISTRIBUTED PRESSURE}

The average pressure on the leaves of an ordinary book as it lies on the table is but a fraction of an ounce per square inch. On the other hand, during the binding process the book may have been subjected to pressures of 40 or $50 \mathrm{lbs}$./in. ${ }^{2}$. In order to simulate to some extent these actual and extreme conditions met with in the life history of a bound volume so as to have a logical basis of comparison for bulk data, a bulking press was improvised by means of which such extremes of pressure, distributed uniformly over the 
entire pack, could be applied. This apparatus is shown schematically in Figure 4. The pack of paper, $P$, was placed on a horizontal surface, $S$, and a thick aluminum plate, $A$, was laid on top of the pack. A dial gage, $G$, was provided for measuring the thickness of the pack at any time. The heavy pressures were applied by means of the lever, $L$, and a suitable weight, $W_{1}$. In applying the small pressures the lever was removed, a tripod, $T$, was placed on the aluminum plate so as to clear the gage, and a suitable weight, $W_{2}$, was added so that the combined load of this weight, the aluminum plate, the tripod, and the gauge pressure would produce the required pressure.

No especial refinements were deemed necessary in applying the heavier pressures, since these were intended primarily to approximate bookbinding pressures, and since, in the study of the pressure bulker, it was found that the amount of pressure preceding a bulk measurement at a comparatively light pressure might vary considerably without affecting appreciably this bulk measurement. However,

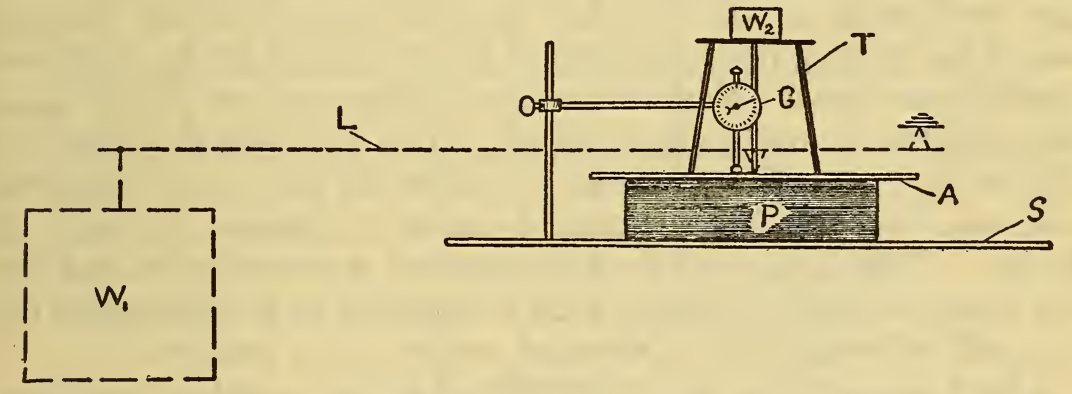

FIGURE 4.-Bulking press

the member serving as a knife-edge in contact with the plate, $A$, was made to extend entirely across the plate in the longer direction of the pack of paper, and both this member and the plate were of sufficiently sturdy construction to insure against appreciable warping of the plate under the heaviest pressures used. All reasonable care was taken to insure that the pressures actually applied through the lever system were approximately those desired in each case.

It was found impracticable to use the extremely low pressures of less than an ounce per square inch, as it was necessary to apply a few ounces per square inch to some of the papers in order to flatten them out sufficiently to give comparable results with the others. A working range of pressures having a minimum of about half a pound and a maximum of about $40 \mathrm{lbs}$./in. ${ }^{2}$ was found feasible for bulk measurements.

Experiments at pressures of a few ounces per square inch showed that the change in thickness per unit change in pressure in this low-pressure region is 'several times that which takes place in the 
neighborhood of $5 \mathrm{lbs}$./in. ${ }^{2}$, as is to be surmised from the shape of the curves of Figure 2. Because of this fact there is a certain disadvantage in working at very low pressures, since a greater degree of precision in applying the pressures is required in the low-pressure region. On the other hand, high pressures are much less significant in bulk measurements, since the thickness of a bound volume in use is determined by relatively small pressures.

The bulking press was further studied in connection with the pressure bulker and the thickness gage, using various pressures in measuring the bulking properties of several kinds of paper.

\section{COMPARATIVE TESTS BY THREE METHODS}

Eleven kinds of paper, selected to represent the most important types in which bulk is a significant factor, were used for these tests. A pack of each, approximately 1 inch in thickness, was tested by means of the bulking press, the pressure bulker, and the thickness gage conforming to the technical association specifications. In the case of the bulking press pressures of $0.5,40,0$, and $0.5 \mathrm{lbs} . /$ in. $^{2}$ were applied in sequence. Next the pressure bulker was used on the same packs, and pressures of $0.5,5,20,40,0,0.5$, and $5 \mathrm{lbs}$./in. ${ }^{2}$ were applied in sequence. Following this procedure the packs were measured with the thickness gage having a constant pressure of about 10 lbs./in. ${ }^{2}$. Then the procedures were repeated in reverse order, and the two values for each procedure were averaged so as to compensate for the small differences due to repeated application of pressure.

A pack thicker than about a quarter of an inch could not be measured with the thickness gage, so each pack was divided into four parts which were measured separately and the sum taken for comparison with the other methods.

It was necessary to modify the pressure bulker in order to get data at a pressure of $0.5 \mathrm{lb}$./in. ${ }^{2}$. Such data were desired in order to determine the feasibility of a design of apparatus having the comparatively large pressure surfaces of the bulker, but dispensing with the screw jack and pressure gauge and using a constant low pressure in conjunction with a means of measuring the thickness of the pack. The pressure bulker was not designed for recording such low pressures, but the required pressure was obtained by taking off the cap screw and weighting the pressure foot by the required amount. It was necessary also to take into consideration the friction in the guide stem, since it was too great to be neglected in this low-pressure region. The pressure was measured, as in the case of the thickness gages, by means of a weighted lever. 
TABLE 2.-Comparative tests

\begin{tabular}{|c|c|c|c|c|c|c|c|c|c|c|c|c|c|c|}
\hline \multirow[b]{2}{*}{ Kind of paper } & \multirow[b]{2}{*}{ 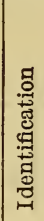 } & \multirow[b]{2}{*}{ 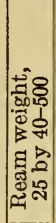 } & \multicolumn{12}{|c|}{ Thickness of 100 sheets (in hundredths of an inch) } \\
\hline & & & 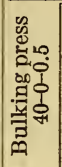 & 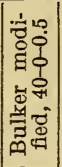 & 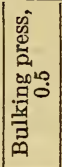 & 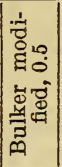 & 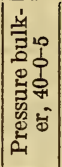 & 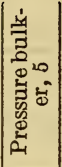 & 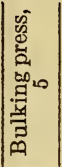 & 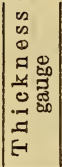 & 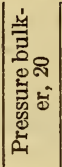 & 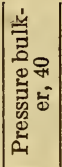 & 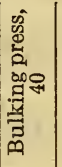 & 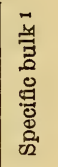 \\
\hline $\begin{array}{l}\text { Writing } \\
\text { Bond } \\
\text { Ledger } \\
\text { Coated book } \\
\text { S. and S. C., boo } \\
\text { Offiset, book...- }\end{array}$ & $\begin{array}{l}\text { W } \\
\text { B } \\
\text { L } \\
\text { C } \\
\text { S } \\
\text { O }\end{array}$ & $\begin{array}{r}\text { Los. } \\
51 \\
65 \\
97 \\
83 \\
53 \\
58\end{array}$ & $\begin{array}{l}35.6 \\
47.0 \\
58.7 \\
40.6 \\
31.6 \\
52.2\end{array}$ & $\begin{array}{l}35.6 \\
47.5 \\
58.7 \\
41.1 \\
31.3 \\
52.2\end{array}$ & $\begin{array}{l}35.9 \\
47.5 \\
58.7 \\
41.1 \\
31.6 \\
53.3\end{array}$ & \begin{tabular}{|l|}
35.9 \\
48.0 \\
59.3 \\
41.1 \\
31.6 \\
52.8
\end{tabular} & \begin{tabular}{|l|}
34.4 \\
46.0 \\
56.9 \\
39.4 \\
30.6 \\
50.6
\end{tabular} & \begin{tabular}{|l|}
34.8 \\
46.0 \\
56.9 \\
39.4 \\
30.6 \\
51.1
\end{tabular} & \begin{tabular}{|l|}
34.4 \\
46.0 \\
56.9 \\
39.4 \\
30.3 \\
50.0
\end{tabular} & $\begin{array}{l}34.6 \\
45.8 \\
56.6 \\
39.4 \\
30.4 \\
50.6\end{array}$ & $\begin{array}{l}34.1 \\
45.0 \\
56.2 \\
38.9 \\
30.0 \\
49.4\end{array}$ & $\begin{array}{l}33.3 \\
44.0 \\
55.6 \\
38.9 \\
29.6 \\
48.9\end{array}$ & \begin{tabular}{|l|}
33.4 \\
44.5 \\
55.6 \\
38.9 \\
29.6 \\
47.8
\end{tabular} & $\begin{array}{r}0.68 \\
.70 \\
.58 \\
.47 \\
.57 \\
.87\end{array}$ \\
\hline $\begin{array}{l}\text { Antique book } \\
\text { "Hibulk" book. } \\
\text { Mimeograph.-. } \\
\text { Standard newspri } \\
\text { Bulky newsprint. }\end{array}$ & $\begin{array}{l}\mathrm{H} \\
\mathrm{M} \\
\mathrm{N} \\
\mathrm{K}\end{array}$ & $\begin{array}{l}54 \\
56 \\
51 \\
37 \\
37\end{array}$ & $\begin{array}{l}51.1 \\
67.8 \\
47.5 \\
37.2 \\
52.2\end{array}$ & $\begin{array}{l}51.7 \\
67.8 \\
48.0 \\
37.6 \\
52.2\end{array}$ & $\begin{array}{l}52.2 \\
69.3 \\
49.0 \\
37.6 \\
53.9\end{array}$ & $\begin{array}{l}52.2 \\
69.3 \\
48.5 \\
37.6 \\
53.3\end{array}$ & $\begin{array}{l}50.0 \\
65.0 \\
46.0 \\
35.2 \\
48.3\end{array}$ & $\begin{array}{l}50.0 \\
65.7 \\
46.5 \\
35.6 \\
48.9\end{array}$ & $\begin{array}{l}50.0 \\
65.0 \\
46.0 \\
36.0 \\
47.8\end{array}$ & $\begin{array}{l}50.0 \\
65.5 \\
46.2 \\
35.4 \\
48.2\end{array}$ & $\begin{array}{l}48.9 \\
63.6 \\
45.0 \\
34.0 \\
46.1\end{array}$ & $\begin{array}{l}47.8 \\
62.1 \\
44.0 \\
32.8 \\
44.4\end{array}$ & $\begin{array}{l}48.3 \\
60.7 \\
44.0 \\
32.8 \\
43.9\end{array}$ & $\begin{array}{r}.93 \\
1.17 \\
.91 \\
.96 \\
1.30\end{array}$ \\
\hline
\end{tabular}

1 Calculated from measurements with thickness gage.

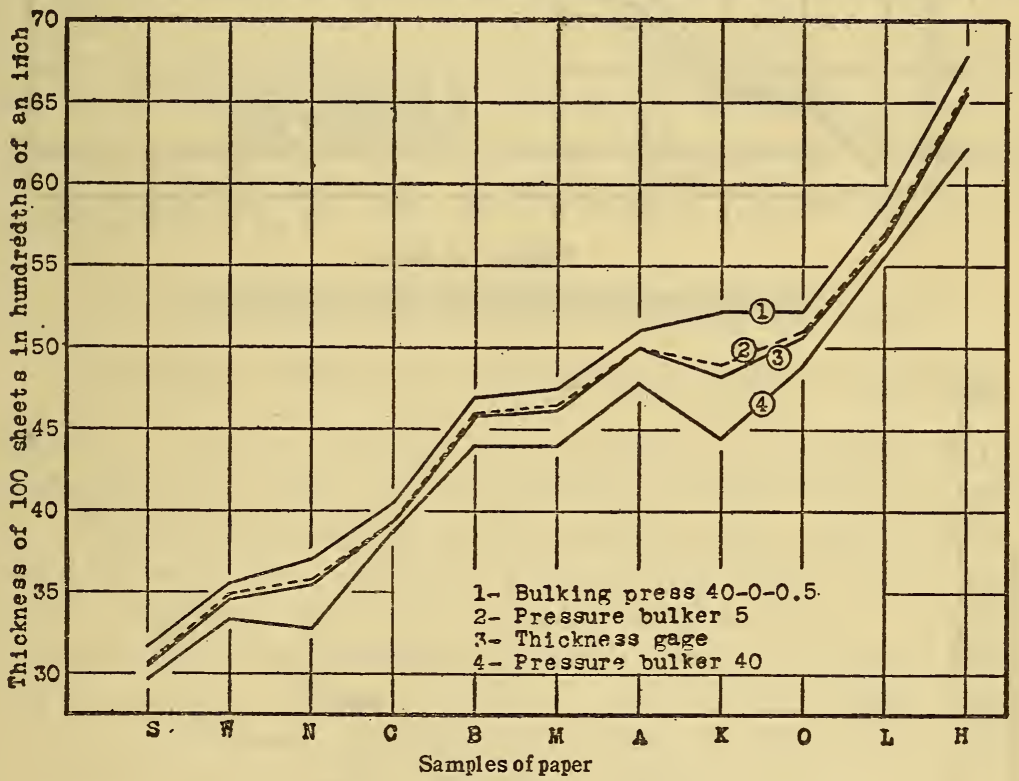

FiguRe 5.-Bulking thickness by different methods

The results of these comparative tests are shown in Table 2 and in Figures 5,6, and 7 . In the table the results are expressed as bulking thickness, or the thickness in hundredths of an inch of a pack of paper consisting of 100 sheets. The pressure applied for each procedure is noted in the heading for that column. For example, the results in the third column, headed "Bulking press, 40-0-0.5," were obtained by applying a pressure of $40 \mathrm{lbs}$./in. ${ }^{2}$ by means of the bulking press, entirely releasing this pressure, and then applying a pressure of 0.5 


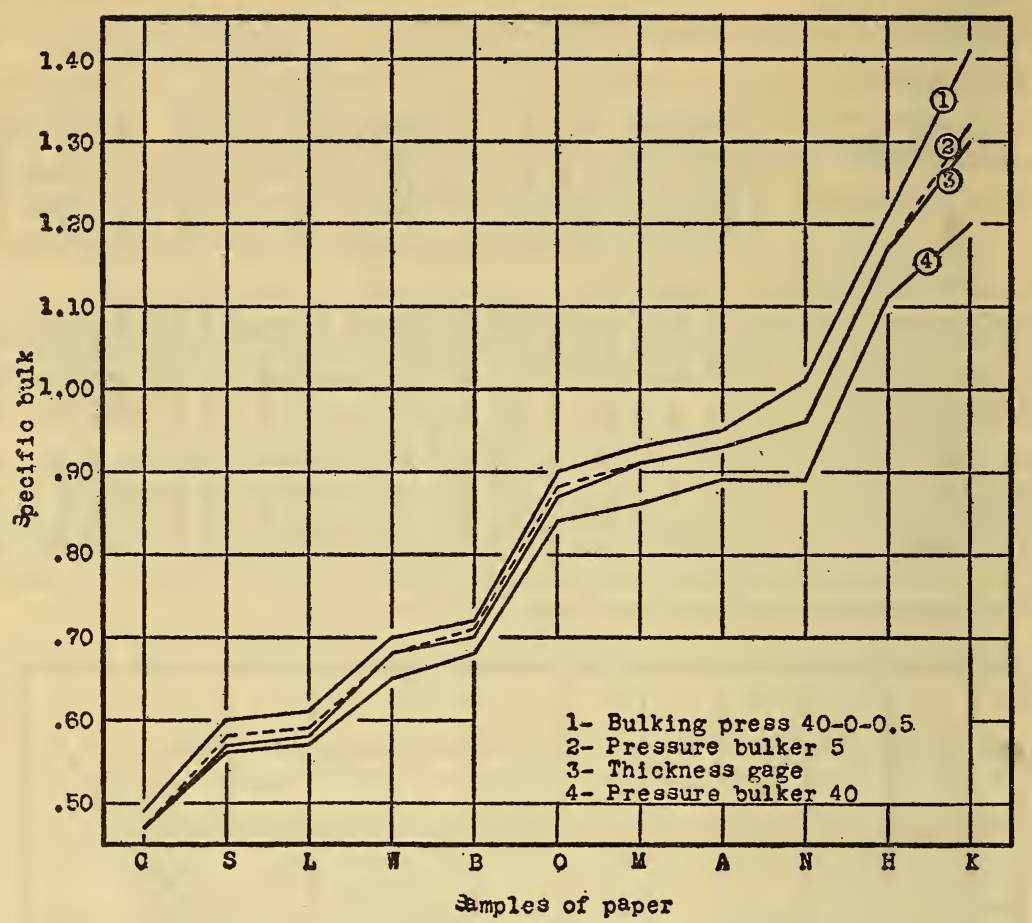

Figure 6.-Specific bulk by different methods

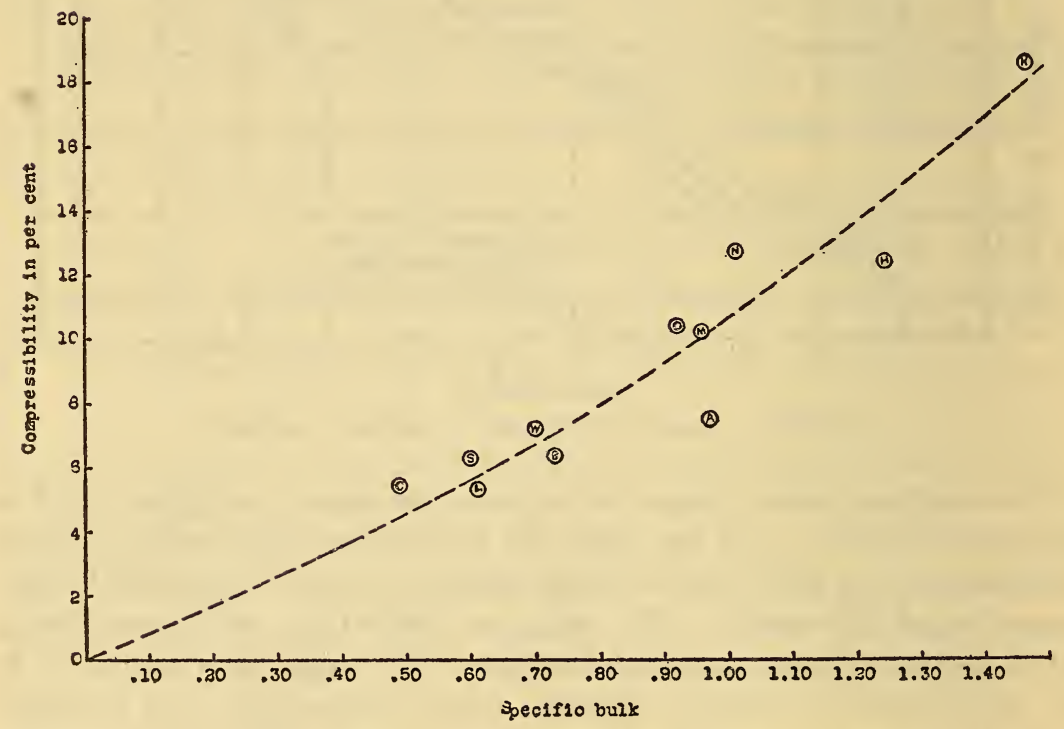

Figure 7.-Relation of compressibility to specific bulk 
lb./in. ${ }^{2}$, immediately after which the thickness of the pack was determined. The weight in pounds of the standard ream of 500 sheets, 25 by 40 inches in area, is given for each kind of paper, as this quantity is required in calculating the specific bulk. An identification symbol is given each kind of paper as a matter of convenience in making the graphic tabulations of Figures 5 and 6 . In these graphs the samples of paper tested are the abscissas, and the values for the quantity determined on each are plotted as ordinates. In Figure 5 the data of Table 2 are plotted for four different procedures in the increasing order of bulking thickness as determined by the procedure first tabulated. In Figure 6 the data, expressed as specific bulk, are plotted in the increasing order of bulk. Specific bulk is proportional to specific volume of the packs and is the ratio of bulking thickness to ream weight. Specific bulk values for the different papers are shown in the last column of Table 2. The relation between specific bulk and compressibility is shown in Figure 7, from which it is seen that they are roughly proportional, as might be expected. Since thickness is not directly proportional to pressure, compressibility is arbitrarily taken as the per cent change in pack thickness when the pressure is increased from 0.5 to $40 \mathrm{lbs}$./in. ${ }^{2}$ in the bulking press. The specific bulk in this case is that at the beginning of the same procedure, at a pressure of $0.5 \mathrm{lb}$./in. ${ }^{2}$.

\section{CONCLUSIONS AND RECOMMENDATIONS}

\section{NEGLIGIBLE EFFECT OF PRELIMINARY HEAVY PRESSURE}

At first it was thought that any method of measuring bulk to be really significant would have to simulate to some extent the conditions of bookbinding which involve rather heavy pressures, as it seemed probable that the heavy pressures used would have an appreciable permanent effect on the thickness of a volume. It was for this reason that in a preliminary report it was recommended that in using the pressure bulker a pressure of $40 \mathrm{lbs}$./in. ${ }^{2}$ should first be applied, then released, and finally a pressure of $5 \mathrm{lbs} . / \mathrm{in} .{ }^{2}$ be applied and the thickness measurement made under this lower pressure. It was for this reason also that the procedure with the bulking press which has been adopted as the reference basis for this series of comparative tests includes a pressure of $40 \mathrm{lbs} . / \mathrm{in} .^{2}$ to precede the light pressure of $0.5 \mathrm{lb} . /$ in. $^{2}$ under which the thickness measurement is made. But the data in Table 2 indicate that the results at any given pressure are pretty much the same regardless of whether or not a heavier pressure has just preceded that at which the thickness measurement was made. 


\section{CHOICE OF METHOD}

The bulking press, which simulates the conditions associated with a bound volume and which has been made the touchstone of the comparative tests herein reported, is not a practical solution of bulk measurement. It is a logical procedure and is excellent for measuring the bulk of a thick pack of paper in sheets of small size. But in practice there may be relatively few sheets and they may be of any size from a few square inches in area to a thousand or more. An apparatus having pressure surfaces a thousand square inches in area would be unwieldy, expensive, and awkward to use and would require means of applying a total load of not less than 500 pounds for a full-size ream of book paper. Such a large pressure foot could scarcely be made light enough or be readily counterbalanced for use with small sheets and small loads without introducing an undesirable amount of friction. The data of Table 2, taken with the modified bulker at a pressure of $0.5 \mathrm{lb} . /$ in. $^{2}$, indicate that an apparatus having pressure surfaces a few square inches in area and designed to exert a small pressure would probably be satisfactory for the measurement of bulk, especially of relatively thick packs of paper. But, despite the fact that existing instruments for bulk measurement are not ideal for the purpose, there are several reasons why it does not seem desirable to recommend the design of a new type of apparatus to displace them. Such an instrument would have to be rather precise and, therefore, expensive in order to give sufficiently accurate results on thin packs, a demand often met with in the practical measurement of bulk. Frequently when a manufacturer is called upon to match a sample of paper for bulk only a small sample has been submitted, and the necessary data must be obtained from a few small sheets. Furthermore, bulk is not usually considered a major property of paper, and the tolerances in the specification of bulk are rather liberal, so that if conditions of operation for existing apparatus can be found which will give consistent relative results approximately paralleling the bulk values for paper in bound volumes it seems preferable to standardize the operation of existing apparatus rather than to create a new type of testing device. In any practical solution of the problem of bulk measurement it appears that only relative values can be obtained anyway, as is indicated by the results with the bulking press which are themselves only relative, since the normal pressure to which a bound volume is subjected is usually less than the smallest pressure found practicable in using the bulking press.

That it is feasible to use existing instruments under certain conditions is indicated by the data shown graphically in Figures 5 and 6 . The results of curve 3 , which were obtained with a thickness gage of standard type, are on the average 97 per cent of the corresponding 
values for curve 1 obtained with the bulking press, and in only one case do they deviate more than 1 per cent from this relative amount. This one exception, the bulky newsprint, is about 4 per cent lower than it should be to stand in the proper relation to the other values. It may be seen from Figures 6 and 7 that this paper is also singular in that it has the highest specific bulk and the greatest compressibility of all the samples tested. It appears from Figure 6 that the results at different pressures tend to diverge with increasing specific bulk and compressibility. (Fig. 7.) In general, therefore, it appears valid to determine relative bulk with the thickness gage, using a pack thick enough to be consistent with the sensitivity of the instrument, and possibly being a little more lenient with the tolerances in the case of very bulky, compressible paper.

As is indicated by curve 2 (figs. 5 and 6), the use of the pressure bulker at a pressure of $5 \mathrm{lbs}$./in. ${ }^{2}$ gives results which agree very closely with those obtained with the thickness gage. It happens that this pressure is a fair compromise between the rather high pressures often used in measuring bulk and the very low pressures which are, perhaps, most significant in connection with bulk. As the pressure is increased above this amount the parallelism becomes less and less satisfactory.

It appears, therefore, that not only is it possible to choose conditions of operation of existing devices which will give satisfactory relative results, but the proper choice of conditions brings the two most widely used instruments for bulk measurement into close agreement.

\section{EXPRESSION OF RESULTS}

Practice differs considerably with respect to the expression of results. Bulk is usually expressed in terms of thickness as a matter of convenience in connection with bookbinding. But some express the results as the number of pages to the inch and others as the thickness of a certain number of pages. The latter seems the more logical of the two, since increasing thickness for a given amount of material varies in the same direction as the concept of increasing bulk. An increasing number of pages to the inch, on the other hand, connotes decreasing bulk. An expression of the number of pages to the inch should be associated with compactness rather than with bulk.

As a result of the usual practice of expressing bulk data in terms of thickness the fundamental concept of bulk is often lost sight of. But primarily bulk is a specific property of paper akin to specific volume, although for the sake of convenience it is not usually so expressed. It seems logical and desirable to recognize two aspects of bulk, which are essentially usages $(a)$ and $(d)$ mentioned in the introduction, and to express the results in two ways: (a) As bulking thickness, to mean the thickness in hundredths of an inch of a 100-sheet pack of paper; and (b) as specific bulk, to mean the ratio of bulking 
thickness to the weight in pounds of the standard ream of 500 sheets, 25 by 40 inches in area. Bulking thickness is then a convenient quantity in connection with bookbinding, and specific bulk is a quantity which expresses the inherent quality of the paper with respect to bulk and is so chosen that the usual book papers have a value in the neighborhood of unity. (See last column of Table 2.)

\section{RECOMMENDED STANDARD PROCEDURE}

A standard testing method and manner of expressing the results of bulk determinations are recommended as follows:

The bulk tests shall be carried out in an atmosphere of standard hygrometric state (65 per cent relative humidity and $70^{\circ} \mathrm{F}$.) as prescribed by the Technical Association of the Pulp and Paper Industry, and the paper to be tested shall have been properly conditioned in this atmosphere. The pack thickness shall be measured by one of the following alternate procedures:

1. A dial thickness gage of a type conforming to the specifications of the Technical Association of the Pulp and Paper Industry ${ }^{1}$ shall be used. A pack of paper not thinner than 0.1 inch shall be measured for thickness on the four corners by means of this gage, a margin of at least half an inch between the pressure foot and the edges of the pack being maintained during the measurement. The average of the four readings shall be used in calculating the bulk values.

2. A pressure bulker shall be used, having a pressure foot not less than 1 square inch in area and being provided with means of applying a definite known pressure of $5 \mathrm{lbs}$./in. ${ }^{2}$ and means of measuring the distance between the pressure surfaces. A pack of paper approximately 1 inch in thickness shall be measured at the four corners between the pressure surfaces of this bulker under a pressure of $5 \mathrm{lbs}$./in. ${ }^{2}$, a margin of at least half an inch between the pressure foot and the edges of the pack being maintained during the measurement. The average of the four readings shall be used in calculating the bulk values.

In either case the results shall be expressed as-

(a) Bulking thickness $=$ Thickness in hundredths of an inch of a 100-sheet pack,

(b) Specific bulk $=\frac{\text { Bulking thickness }}{\text { Weight of standard ream (25 by 40-500) in pounds }}$

Washington, July 10, 1928.

\footnotetext{
${ }_{1}$ Paper testing methods, p. 55; 1928.
} 